\title{
Perbandingan Hasil Belajar Kognitif Siswa Melalui Model Pembelajaran Quick on The Draw dan Discovery Learning di SMA Negeri 4 Kendari
}

\author{
Santi $^{1}$; Rosmini ${ }^{2}$ St. Kuraedah ${ }^{2}$; Masdin $^{2}$ \\ 1) Alumni Prodi Tadris Biologi, Fakultas Tarbiyah dan Ilmu Keguruan (FTIK), Institut Agama Islam Negeri \\ (IAIN) Kendari; \\ ${ }^{2)}$ Dosen FTIK, IAIN Kendari \\ Email Korespondensi: rosmini.gesit@gmail.com
}

\begin{abstract}
This article was aims to determine differences in students' cognitive learning outcomes after being taught using the Cooperative Learning model of the type Quick on The Draw and after being taught using the Discovery Learning model on respiratory system material in SMA Negeri 4 Kendari. This type of research is quantitative research, with a quasi-experimental research method. Data analysis techniques were performed using descriptive and inferential statistical analysis. The samples in this study were class XI MIA 1 (experimental class) and class XI MIA 3 (control class), each with 25 students. The sampling technique is done by using purposive sampling technique. The results showed that there were significant differences in students' cognitive learning outcomes after being taught using the Cooperative Learning model type Quick on The Draw and after being taught using the Discovery Learning model on respiratory system material at SMA Negeri 4 Kendari obtained from student learning outcomes (tested using an Independent test Sample t-test), namely tcount 5.96 and ttable 2.01 with a significance level of 5\%, so tcount 5.96> ttable 2.01 then HO is rejected, meaning that there are significant differences in student learning outcomes after using the Quick Type Cooperative Learning model on The Draw and Discovery Learning models.
\end{abstract}

Keywords: Cognitive Learning Outcomes, Quick On The Draw, Discovery Learning.

\begin{abstract}
ABSTRAK
Artikel ini bertujuan untuk mengetahui perbedaan hasil belajar kognitif siswa sesudah diajar dengan menggunakan model Cooperatif Learning tipe Quick on The Draw dan sesudah diajar menggunakan model Discovery Learning pada materi sistem pernapasan di SMA Negeri 4 Kendari. Jenis penelitian ini ialah penelitian kuantitatif, dengan metode penelitian quasi eksperimen. Teknik analisis data dilakukan dengan menggunakan analisis statistik deskriptif dan inferensial. Sampel pada penelitian ini yaitu kelas XI MIA 1 (kelas eksperimen) dan kelas XI MIA 3 (kelas kontrol), masing-masing sebanyak 25 siswa. Teknik pengambilan sampel dilakukan dengan menggunakan teknik purposive sampling. Hasil penelitian menunjukkan bahwa terdapat perbedaan yang signifikan hasil belajar kognitif siswa sesudah diajar menggunakan model Cooperatif Learning tipe Quick on The Draw dan sesudah diajar menggunakan model Discovery Learning pada materi sistem pernapasan di SMA Negeri 4 Kendari yang diperoleh dari hasil belajar siswa (diuji menggunakan uji Independen Sampel t-test) yaitu $t_{\text {hitung }} 5,96$ dan $t_{\text {tabel }} 2,01$ dengan taraf signifikansi 5\%, sehingga $\mathrm{t}_{\text {hitung }} 5,96>\mathrm{t}_{\text {tabel }} 2,01$ maka $\mathrm{H}_{0}$ ditolak, artinya terdapat perbedaan yang signifikan hasil belajar siswa sesudah menggunakan model Cooperatif Learning Tipe Quick on The Draw dan model Discovery Learning.
\end{abstract}

Kata Kunci: Hasil Belajar Kognitif, Quick On The Draw, Discovery Learning.

\section{PENDAHULUAN}

Terkait perkembangan kurikulum bahwa kurikulum pendidikan di Indonesia telah berganti berkali-kali sejak merdeka. Pada hakikatnya pengembangan kurikulum tersebut merupakan usaha untuk mencari bagaimana rencana dan pengaturan mengenai tujuan, isi, dan bahan pelajaran serta cara yang digunakan sebagai pedoman penyelenggaraan kegiatan pembelajaran yang sesuai dengan perkembangan dan kebutuhan untuk mencapai tujuan tertentu dalam suatu lembaga.

Namun pada kenyataannya, terkait sering bergantinya kurikulum banyak tenaga pendidik atau guru yang belum sempat memahami tujuan dari kurikulum yang ditetapkan sehingga tidak mampu mengaplikasikan kurikulum yang ditetapkan sesuai dengan pembelajaran. Pada saat ini kurikulum yang digunakan adalah kurikulum 2013 dimana siswa dituntut agar dalam proses pembelajaran bukan hanya mempunyai kemampuan kognitif, akan tetapi harus mempunyai kemampuan afektif serta psikomotorik.

Guru sebagai salah satu komponen dalam pembelajaran yakni memiliki posisi yang sangat menentukan keberhasilan dalam proses pembelajaran, karena fungsi utama guru ialah merancang, mengelola, melaksanakan dan mengevaluasi pembelajaran. Disamping itu, kedudukan guru juga sangat strategis dan menentukan. Dikatakan strategis karena guru yang akan menentukan kedalaman dan keluasan materi pelajaran, sedangkan 
bersifat menentukan karena guru yang memilah dan memilih bahan pelajaran yang akan disajikan kepada peserta didik. Salah satu faktor yang dapat mempengaruhi keberhasilan tugas guru, ialah kinerjanya didalam merencanakan/merancang, melaksanakan dan mengevaluasi proses pembelajaran.

Namun fakta yang terjadi pada saat ini, guru kurang mengoptimalkan dirinya sebagai fasilitator dan pendidik, yakni belum menciptakan suasana pembelajaran yang menyenangkan, tidak menerapkan dan menggunakan metode maupun model pembelajaran yang dapat meningkatkan motivasi belajar siswa. Sehingga muncul rasa ketidakingintahuan dalam diri siswa mengenai materi yang akan diajarkan oleh seorang guru.

Salah satu hal yang dapat menentukan keberhasilan seorang guru adalah penggunaan model belajar yang sesuai dengan materi yang sedang dipelajari agar peserta didik mampu menangkap pelajaran dengan mudah, menguasai konsep serta aktif dalam kegiatan belajar mengajar di kelas.

Oleh sebab itu, untuk mencapai hal tersebut diperlukan suatu model pembelajaran yang dapat meningkatkan motivasi dan hasil belajar siswa. Salah satu model pembelajaran yang dapat digunakan adalah model Cooperatif Learning tipe Quick on The Draw dan model Discovery Learning. Model pembelajaran Cooperatif Learning tipe Quick on The Draw merupakan suatu pembelajaran yang memberikan kesempatan kepada siswa untuk memahami materi pelajaran dengan kemampuannya sendiri. Model ini memuat unsur permainan di dalamnya berupa perlombaan kecepatan antar kelompok dengan menyelesaikan pertanyaanpertanyaan dalam suatu set kartu dengan mencari jawaban langsung dari materi sumbernya. Selain dapat membuat siswa tertarik dengan unsur permainan dan penuh kegembiraan, siswa juga mau tidak mau harus membaca dan memahami sumber materi agar dapat meyelesaikan permainan tersebut (Sardirman, 2012). Adapun model pembelajaran Discovery Learning merupakan pembelajaran yang mempunyai kaitan intelektual yang jelas dengan pembelajaran berdasarkan masalah. Pada kedua model ini, guru menekankan keterlibatan peserta didik secara aktif, orientasi induktif lebih ditekankan daripada deduktif, dan peserta didik menemukan atau mengosntruksi pengetahuan mereka sendiri. Tidak seperti pada pembelajaran langsung, yang mana peserta didik diberikan ide-ide atau teori tentang dunia. Pada pembelajaran penemuan, guru mengajukan pertanyaan dan memperbolehkan peserta didik untuk menemukan ide dan teori mereka sendiri (Huda, 2013).

Pada penelitian ini terkait perbandingan model Cooperatif Learning tipe Quick on The Draw dan model Discovery Learnig, belum ada peneliti terdahulu yang melakukan penelitian ini di SMA Negeri 4 Kendari. Sehingga dari hasil penelitian yang dilakukan peneliti, diharapkan dapat memberikan kontribusi terkait ide-ide penggunaan model pembelajaran yang menarik sesuai dengan kurikulum 2013 dan materi yang akan diajarkan oleh guru serta dapat menarik motivasi dan minat belajar siswa tentang materi yang akan diajarkan.

\section{METODE PENELITIAN}

Penelitian ini merupakan penelitian kuantitatif metode eksperimen. Penelitian ini dilakukan di SMA Negeri 4 Kendari. Populasi penelitian ini adalah seluruh siswa kelas XI MIA SMAN 4 Kendari yang berjumlah 10 kelas. Teknik pengambilan sampel dalam penelitian ini yaitu purposive sampling yaitu penentuan sampel berdasarkan tujuan-tujuan tertentu yang telah ditetapkan serta mewakili karakteristik dari populasi (Sony dan Bagya, 2017), dalam hal ini dengan melihat nilai rata-rata yang sama atau hampir sama sehingga kelas yang dijadikan sampel yaitu XI MIA 1 dengan nilai rata-rata 83,5 dan jumlah siswa yang dijadikan sampel dalam penelitian 25 orang. Serta kelas XI MIA 3 dengan nilai rata-rata 83 dengan jumlah siswa 25 orang. Pengambilan sampel secara random untuk menentukan kelas eksperimen dan kelas kontrol, dilakukan dengan cara undian. Oleh sebab itu, kelas yang akan dijadikan sampel sebagai kelas eksperimen adalah XI MIA 1 dan sebagai kelas kontrol adalah XI MIA 3. Variabel pada penelitian ini terdiri atas variabel bebas yaitu model Cooperatif Learning Tipe Quick on The Draw (X1) dan model Discovery Learning (X2) dan variabel terikat yaitu hasil belajar kognitif siswa (Y). Desain yang digunakan adalah pretest-posttest control group design (Winarno, 2011).

Instrumen penelitian dan teknik pengumpulan data dalam penelitian ini yaitu melalui tes, observasi dan dokumentasi. Uji validitas dalam penelitian ini menggunakan rumus product moment dan untuk uji reliabilitas pada penelitian ini menggunakan rumus KR-20 (Kuder Richardson), (Suharsimi, 2003).

Teknik analisis data yang digunakan dalam penelitian ini yaitu analisis deskriptif dan analisis inferensial. Analisis deskriptif digunakan untuk menganalisis data dengan cara mendeskripsikan data yang telah terkumpul tanpa menarik kesimpulan atas populasi yang diamati. Teknik analisis deskriptif dilakukan dengan mencari nilai rata-rata (Muhammad, 2007) dan standar deviasi (Agung, 2016). Analisis inferensial digunakan untuk pengujian hipotesis penelitian. Uji hipotesis penelitian dilakukan dengan langkah-langkah: pengujian prasyarat analisis dengan uji normalitas menggunakan rumus Kolmogorof Smirnov. Sedangkan uji homogenitas yang digunakan untuk dua buah peubah bebas (independen) yaitu uji homogenitas menggunakan uji F (Agung, 2016).

Uji hipotesis perbedaan kedua rata-rata kelas eksperimen dan kelas kontrol dilakukan dengan uji t, sebagaimana persyaratan uji t data antara kelas eksperimen dan kela kontrol harus berdistribusi normal dan homogen. Jenis uji t yang digunakan yaitu independen sampel t-test (Nuryadi, dkk., 2017). 


\section{HASIL PENELITIAN}

Perbedaan hasil belajar kognitif siswa dapat dilihat dengan membandingkan hasil setiap perlakuan yaitu sesudah diajar menggunakan model Cooperatif Learning Tipe Quick on The Draw pada kelas eksperimen dan sesudah menggunakan model Discovery Learning pada kelas kontrol. Untuk melihat adanya perbedaan tersebut dilakukan uji perbedaan rata-rata menggunakan uji t. Akan tetapi terlebih dahulu dilakukan uji prasyarat analisis yaitu uji normalitas dan uji homogenitas.

1. Rata-rata Nilai Hasil Belajar Kognitif Siswa Sesudah Diajar Menggunakan Model Cooperatif Learning Tipe Quick on The Draw dan Sesudah Menggunakan Model Discovery Learning

Data hasil penelitian tentang perbandingan hasil belajar kognitif siswa sesudah diajar menggunakan model Cooperatif Learning Tipe Quick on The Draw dan sesudah menggunakan model Discovery Learning disajikan pada tabel berikut.

Tabel 1. Rata-rata Nilai Hasil Belajar Kognitif Siswa

\begin{tabular}{|c|l|c|c|}
\hline No & \multicolumn{1}{|c|}{ Statistik } & Kelas Eksperimen & Kelas Kontrol \\
\hline 1 & Nilai tertinggi & 92 & 92 \\
\hline 2 & Nilai terendah & 63 & 41 \\
\hline 3 & Rata-rata & 85,4 & 77,76 \\
\hline 4 & Standar deviasi & 6,31 & 11,06 \\
\hline
\end{tabular}

Sumber: dianalisis menggunakan perhitungan manual

Berdasarkan tabel diatas rata-rata nilai hasil belajar kognitif siswa pada kelas eksperimen yaitu 85,4 dan pada kelas kontrol 77,76. Adapun distribusi frekuensi data hasil belajar kognitif siswa sesudah diajar menggunakan model Cooperatif Learning Tipe Quick on The Draw dan sesudah menggunakan model Discovery Learning disajikan pada gambar berikut.
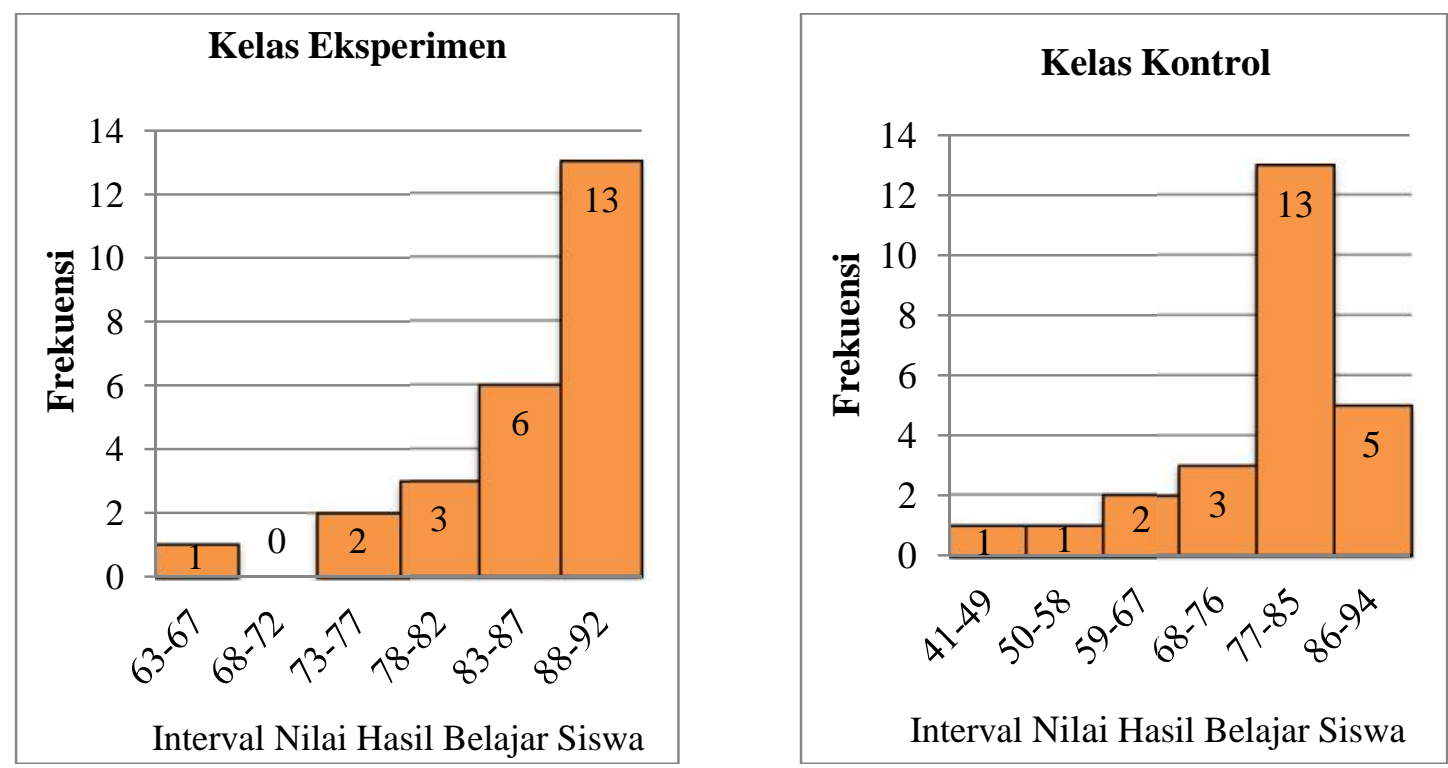

\section{Gambar 1. Distribusi Frekuensi Data Hasil Belajar Siswa Sebelum Dan Sesudah Menggunakan Model Discovery Learning}

Berdasarkan gambar diatas bahwa pada kelas eksperimen nilai tertinggi berada pada interval 88-92 sebanyak 13 orang dengan perolehan persentase sebesar 52\% dan nilai terendah berada pada interval 63-67 sebanyak 1 orang dengan perolehan persentase sebesar $4 \%$. Sedangkan pada kelas kontrol nilai tertinggi berada pada interval 86-94 sebanyak 5 orang dengan perolehan persentase sebesar $20 \%$ dan nilai terendah berada pada interval 41-49 sebanyak 1 orang dengan perolehan persentase sebesar 4\%. Sehingga dapat diartikan bahwa nilai hasil belajar kognitif siswa pada kelas eksperimen lebih tinggi daripada kelas kontrol. 


\section{Uji Prasyarat Analisis}

Sebelum pengujian hipotesis, terlebih dahulu dilakukan uji prasyarat yaitu uji normalitas dan uji homogenitas, yaitu sebagai berikut.

Tabel 2. Hasil Pengujian Normalitas Data

\begin{tabular}{|c|c|c|c|c|}
\hline \multirow{2}{*}{ Kelompok } & \multicolumn{3}{|c|}{ Kolmogorof - Smirnof } & \multirow{2}{*}{ Keterangan } \\
\cline { 2 - 4 } & $\left|F_{t}-F_{S}\right|$ & $\mathbf{N}$ & $\boldsymbol{\alpha} \mathbf{( 5 \% )}$ & Normal \\
\hline Eksperimen & 0,00 & 25 & 0,264 & Normal \\
\hline Kontrol & 0,02 & 25 & 0,264 & . \\
\hline
\end{tabular}

Sumber: Perhitungan Menggunakan Aplikasi Microsoft. Excel

\section{Kriteria:}

Jika $\left|F_{t}-F_{s}\right|$ nilai tabel Kolmogorof - Smirnof $\alpha(5 \%)=$ berdistribusi normal

Jika $\left|F_{t}-F_{s}\right|>$ nilai tabel Kolmogorof - Smirnof $\alpha(5 \%)=$ tidak berdistribusi normal

Tabel 3. Hasil Pengujian Homogenitas Data

\begin{tabular}{|c|c|c|c|c|}
\hline \multirow{2}{*}{ Hasil Belajar Siswa } & \multicolumn{3}{|c|}{ Homogenitas } & \multirow{2}{*}{ Keterangan } \\
\cline { 2 - 5 } & $\mathbf{f}_{\text {hitung }}$ & Signifikansi $\boldsymbol{\alpha}(\mathbf{5 \%})$ & $\mathbf{f}_{\text {tabel }}$ & Homogen \\
\hline Sesudah perlakuan & 1,75 & $\mathrm{t}_{(0,05)(24 ; 24)}$ & 1,98 & Hom \\
\hline
\end{tabular}

Sumber: Perhitungan Menggunakan Aplikasi Microsoft. Excel

\section{Kriteria:}

Jika $\mathrm{F}_{\text {hitung }} \mathrm{F}_{\text {tabel }}=$ homogen

Jika $\mathrm{F}_{\text {hitung }}>\mathrm{F}_{\text {tabel }}=$ tidak homogen

\section{Uji Hipotesis}

Tabel 4. Uji Perbedaan Hasil Belajar Kognitif Siswa Sesudah Diajar Dengan Menggunakan Model Cooperatif Learning Tipe Quick On The Draw dan Sesudah Diajar Dengan Menggunakan Model Discovery Learning

\begin{tabular}{|c|c|c|c|}
\hline Hasil Belajar Siswa & $\mathbf{T}_{\text {hitung }}$ & $\mathbf{T}_{\text {tabel }(\mathbf{0 , 0 5} ; \mathbf{2 2})}$ & Keterangan \\
\hline Sesudah perlakuan & 5,96 & 2,01 & Signifikan \\
\hline
\end{tabular}

Berdasarkan tabel diatas bahwa bahwa uji perbedaan hasil belajar siswa sesudah menggunakan model Cooperatif Learning Tipe Quick on The Draw pada kelas eksperimen dan model Discovery Learning pada kelas kontrol diperoleh hasil belajar siswa $t_{\text {hitung }} 5,96$ dan $t_{\text {tabel }}$ 2,01 dengan taraf signifikansi 5\%, sehingga $t_{\text {hitung }} 5,96>\mathrm{t}_{\text {tabel }} 2,01$ maka $\mathrm{H}_{0}$ ditolak, yang artinya terdapat perbedaan yang signifikan hasil belajar siswa sesudah menggunakan model Cooperatif Learning Tipe Quick on The Draw dan model Discovery Learning.

\section{PEMBAHASAN}

Dalam proses pembelajaran pada penelitian ini dilakukan dua perlakuan yang berbeda yaitu menggunakan model Cooperative Learning tipe Quick on The Draw pada kelas eksperimen dan menggunakan model Discovery Learning pada kelas kontrol. Setelah pembelajaran berakhir, kelas eksperimen dan kelas kontrol diberi tes akhir (posttest) yang sama untuk mengetahui hasil belajar kognitif siswa dari perlakuan yang berbeda tersebut.

Hasil analisis uji perbedaan hasil belajar kognitif siswa menunjukkan bahwa $t_{\text {hitung }} 5,96>t_{\text {tabel }} 2,01$ artinya terdapat perbedaan yang signifikan hasil belajar siswa sesudah diajar dengan menggunakan model Cooperatif Learning Tipe Quick on The Draw dan sesudah diajar menggunakan model Discovery Learning. Dari hasil tersebut, bahwa hasil belajar kognitif siswa menggunakan model Cooperatif Learning Tipe Quick on The Draw lebih tinggi daripada menggunakan model Discovery Learning. Hal ini juga dapat dilihat pada lembar hasil observasi aktivitas siswa dalam mengikuti setiap tahap-tahap dalam pembelajaran Quick on The Draw diperoleh nilai rata-rata sebesar 96,58 \% lebih tinggi daripada hasil observasi aktivitas siswa dalam pembelajaran Discovery Learning dengan nilai rata-rata sebesar 93,25\%.

Pada proses pembelajaran Quick on The Draw siswa sangat antusias dan aktif dalam mengikuti pembelajaran sebab di dalamnya mengandung unsur permainan dan perlombaan antar kelompok untuk 
menyelesaikan satu set pertanyaan. Sehingga masing-masing kelompok saling berusaha untuk jadi pemenangnya. Dibandingkan dengan pembelajaran Discovery Learning, siswa memang terlibat untuk aktif dalam mengikuti setiap tahap pembelajaran akan tetapi minat dan motivasi masing-masing kelompok dalam menjawab soal LKS yang diberikan guru dianggap seperti hal biasa terkadang kurang kerjasama masing-masing kelompok.

Kegiatan pembelajaran Quick on The Draw memiliki aktivitas yang di dalamnya membantu siswa untuk membiasakan diri belajar pada berbagai sumber dan meningkatkan ketertarikan siswa untuk lebih aktif sehingga memberikan pengalaman mengenai macam-macam keterampilan membaca, sebab di dalam pembelajaran ini siswa diajak bermain sambil belajar. Sedangkan kegiatan pembelajaran Discovery Learning memerlukan kesiapan pikiran untuk belajar, bagi siswa yang kurang pandai akan mengalami kesulitan berpikir untuk mengungkapkan hubungan antara konsep-konsep baik tertulis maupun lisan sehingga akan menimbulkan frustasi, membutuhkan waktu yang lama untuk membantu mereka menemukan teori atau pemecahan masalah lainnya. Dengan demikian penggunaan model Cooperatif Learning Tipe Quick on The Draw lebih baik daripada model Discovery Learning pada materi sistem pernapasan.

Menurut Prabesti dalam penelitiannya bahwa pembelajaran Quick on The Draw dapat membuat siswa terlibat secara aktif di dalam kelas karena mereka dituntut menguasai konsep-konsep materi yang sedang dipelajari baik secara individu maupun berdiskusi dengan teman-teman kelompoknya (Prabesti, 2016). Sesuai dengan yang diamanatkan oleh Peraturan Menteri Pendidikan Nasional Republik Indonesia nomor 40 tahun 2007 tentang standar proses pembelajaran harus dilaksanakan sebagai berikut: "kegiatan pembelajaran harus dilakukan secara interaktif, inspiratif, menyenangkan, menantang, memotivasi siswa untuk berpartisipasi aktif serta memberikan ruang yang cukup bagi prakarsa, kreativitas, dan kemadirian sesuai dengan bakat, minat, dan perkembangan fisik serta psikologis peserta didik.

Adanya perbedaan yang signifikan hasil belajar kognitif siswa menggunakan model Cooperative Learning tipe Quick on The Draw dan model Discovery Learning menunjukkan bahwa model Cooperative Learning tipe Quick on The Draw lebih unggul dari pada model Discovery Learning dalam meningkatkan hasil belajar kognitif siswa. Dalam proses pembelajaran Quick on The Draw memberikan suasana kompetisi selama proses pembelajaran dan siswa saling berlomba untuk menjadi kelompok tercepat dalam menyelesaikan kartu pertanyaan dengan baik dan benar. Dengan adanya persaingan ini melatih siswa untuk berpikir secara cepat dan tepat. Hal ini sesuai dengan pendapat Machin dalam penelitiannya bahwa dengan adanya permainan menciptakan suasana kelas yang lebih hidup dan menyenangkan, sehingga antusiasme siswa dalam proses pembelajaran semakin bertambah, siswa juga dilibatkan secara langsung dalam permainan serta dengan adanya suasana kompetitif selama permainan dapat memicu siswa untuk menjadi yang terbaik diantara siswa lainnya (Machin, 2015).

Selain itu, dalam mengajar seorang pendidik hendaklah berusaha agar peserta didik tidak merasa bosan dengan penyampaian sipendidik. Dengan demikian metode dan strategi belajar haruslah sesuai dengan meteri pelajaran, situasi peserta didik dan kemampuannya (Suryani, 2012).

\section{KESIMPULAN}

Terdapat perbedaan yang signifikan hasil belajar kognitif siswa kelas XI MIA 1 sesudah diajar menggunakan model Cooperatif Learning tipe Quick on The Draw dan siswa kelas XI MIA 3 sesudah diajar menggunakan model Discovery Learning pada materi sistem pernapasan di SMA Negeri 4 Kendari yang diperoleh dari hasil belajar siswa $t_{\text {hitung }} 5,96$ dan $t_{\text {tabel }} 2,01$ dengan taraf signifikansi 5\%, sehingga $t_{\text {hitung }} 5,96>t_{\text {tabel }}$ 2,01 maka $\mathrm{H}_{0}$ ditolak, yang artinya terdapat perbedaan yang signifikan hasil belajar siswa sesudah menggunakan model Cooperatif Learning Tipe Quick on The Draw dan model Discovery Learning.

\section{DAFTAR PUSTAKA}

A. Machin. (2010). Pengaruh Permainan Call Cards Terhadap Hasil belajar dan Aktivitas Pembelajaran Biologi. Jurnal Pendidikan IPA Indonesia, 1 (2), h. 13.

Arikunto, Suharsimi. (2003). Dasar-Dasar Evaluasi Pendidikan. Jakarta: Bumi Aksara, h. 253 dan 110.

Gede, Anak Agung. (2016). Statistik Dasar Untuk Pendidikan. Yogyakarta: Deepublish, h. 72.

Miftahul, Huda. (2013). Model-model Pengajaran dan Pembelajaran. Yogyakarta: Pustaka Pelajar, 49.

Nuryadi, dkk. (2017). Dasar-dasar Statistik Penelitian. Yogyakarta: Sibuku Media, h. 101-109.

Rinaldi, Sony Faisal dan Bagya Mujianto. (2017). Metodologi Penelitian dan Statistik, Pusat Pendidikan Sumber Daya Manusia Kesehatan, h. 80. 
Safitri, Nur Ayu, Andi Maulana dan Eka Damayanti. (2018). Pengaruh Penerapan Pembelajaran Quick on The Draw Terhadap Motivasi dan Hasil Belajar Siswa SMP Negeri 3 Palangga. Jurnal Biotek, 6 (1), h. 3.

Sardirman. (2012). Interaksi dan Motivasi Belajar Mengajar. Jakarta: PT Raja Grafindo Persada, h. 49.

Suryani. (2012). Hadis Tarbawi Analisis Paedagogis Hadis-Hadis Nabi. Yogyakarta: Teras, h. 79-80.

Tiro, Muhammad Arif. (2007). Dasar-dasar Statistik. Makassar : Makassar State University Of Makassar, h. 133.

Winarno, M. E. (2011). Metodologi Penelitian Dalam Pendidikan Jasmani Malang: UM Press, h. 64. 